\title{
Influences of Berry Size on Fruit Composition and Wine Quality of Vitis vinifera L. cv. 'Cabernet Sauvignon' Grapes
}

\author{
Wei-Kai Chen ${ }^{1,2}$, Fei He ${ }^{1,2}$, Yu-Xi Wang ${ }^{1,2}$, Xin Liu ${ }^{1,2}$, Chang-Qing Duan ${ }^{1,2}$, Jun Wang ${ }^{1,2, *}$ \\ (1) Centre for Viticulture and Oenology, College of Food Science and Nutritional Engineering, China Agricultural University, \\ Beijing 100083, China \\ (2) Key Laboratory of Viticulture and Oenology, Ministry of Agriculture, Beijing 100083, China
}

Submitted for publication: July 2017

Accepted for publication: January 2018

Keywords: Berry size, wine grape, phenolic compounds, volatile compounds, natural variation

\begin{abstract}
The heterogeneity of berry heterogeneity is a commonly occurring phenomenon that has a big influence on fruit composition and wine quality. To clarify this relationship, 'Cabernet Sauvignon' grapes were collected at harvest from a single vineyard and divided into three categories in two consecutive years: small ( $\leq$ 0.75 g), medium (0.76-1.25 g), and large ( $>1.25 \mathrm{~g})$. The medium berries were present in the highest frequency, accounting for more than $50 \%$ of the berry populations. The standard physicochemical parameters of the fruit were significantly affected by berry size. The relative skin mass and soluble solids contents, as well as total phenolic and anthocyanin concentrations, decreased with the berry size, while the relative seed mass, $\mathrm{pH}$ and malic acid content were positively correlated with berry weight. Accordingly, the wine composition also varied with berry size, as the wines made from small berries showed the highest alcohol and residual sugar content. CIELab parameters of the resulting wines showed the small berries were more desirable for making wine with a deeper and more saturated colour. With regard to volatile compounds, berry size showed a limited effect. Only 1-hexanol and laevo-2,3-butanediol showed consistent and significant trends across vintages for wine volatiles, which showed the highest levels in wines made from the small category of berries.
\end{abstract}

\section{INTRODUCTION}

Berry size is an important factor determining fruit and wine quality (Gil et al., 2015; Melo et al., 2015). As for wine grapes, especially the red grape varieties, it is generally accepted that relatively small berries give excellent wine quality (Singleton, 1972; Matthews \& Anderson 1988). This concept arose from the recognition that the amount of skin changes with berry size in accordance with the ratio of skin surface area to flesh volume (Roby \& Matthews, 2004; Roby et al., 2004). On one hand, small berries have a higher surface:volume ratio and more solutes per skin, since several important constitutes accumulate in the skin. On the other hand, large berries have a greater solvent-to-solute ratio and the extracted solutes from skins are easier diluted (Matthews \& Anderson, 1988). Interestingly, a recent paper found that the skin-to-flesh ratio of small and large berries of Cabernet Sauvignon was constant in irrigation trials, as the smaller berries from severe irrigation deficits had thinner skins (Cooley et al., 2017).

Tissue constituents and chemical composition of grape berries are closely correlated with berry size (Roby \& Matthews, 2004; Roby et al., 2004). This includes the accumulation of sugars, degradation of organic acids, and production of various secondary metabolites, which have a great influence on the uniformity of grape ripeness and on wine quality. Red grape skins represent a rich source of phenolic compounds, especially anthocyanins, which is largely related to the resulting wine colour (Gil et al., 2015). The volatile composition of the grape berry is another important factor that determines the wine aroma and flavour. However, only a few experiments have been designed to explore the relationship among berry size, sensory evaluation and wine quality. However, some researchers have claimed that berry size does not have great effects on wine aroma, or at least that the effects are not straightforward (Walker et al., 2005; Holt et al., 2008). Some other studies have reported that berry weight is correlated with the wine style, and that the small or medium ones might be better (Melo et al., 2015). Thus, great efforts are still necessary in the investigation of the impact of berry size on wine quality.

Multiple factors exert their influences on berry weight, leading to size variability among berries within the cluster, among clusters within the vine, among vines within the vineyard, and among vineyards (Shellie, 2010; Pisciotta et al., 2013). Irrespective of cultivar characteristics, berry size is dependent not only on intrinsic factors of genotype and clonal variants (Fernandez et al., 2006; Houel et al.,

*Corresponding author: E-mail address: jun_wang@cau.edu.cn [Tel.: 86-010-62738537; Fax: 86-010-62738658]

Acknowledgements: The authors wish to thank the China Agriculture Research System (CARS-29), for financial support 
2013), but also on extrinsic factors, such as environmental conditions and viticultural practices (Matthews \& Anderson, 1988; Roby \& Matthews, 2004; Petrie \& Clingeleffer, 2006; Holt et al., 2008). Several treatments in the vineyard, such as deficit irrigation (Kennedy et al., 2002; Roby et al., 2004), high crop load (Bravdo et al., 1985), lighter pruning strategies (Holt et al., 2008), rootstock choice (Keller et al., 2011) and even canopy management (Smart et al., 1990), can affect berry size and therefore exert an influence on the subsequent wine quality attributes. Moreover, shading treatment during fruit development could result in smaller berries than those exposed to light (Dokoozlian \& Kliewer, 1996). Additionally, the natural variation or 'millerandage' ('hens and chickens') could also result in berry size heterogeneity (Keller, 2010). These phenomena confirm the wide existence of berry size heterogeneity, which is the integrated effect of many biotic and abiotic factors, and therefore exerts a great influence on grape and wine quality (Melo et al., 2015).

In order to further explore the influences of berry size on the qualities of grapes and wine, the present study was conducted on Cabernet Sauvignon grapes at commercial harvest in two consecutive years. It is worth noting that the berry size heterogeneity here resulted from natural variation, and the present study avoided confounding effects associated with crop load, etc., because those berries were selected from the same vines. The grape berries were divided into three categories according to berry weight, and the variations in wine grape qualities were surveyed in several quantifiable aspects, such as standard physicochemical parameters, organic acids, anthocyanin and total phenolics. Red wines made from different-sized berries were analysed in terms of colour characteristics, anthocyanins, total phenolics and volatile compounds.

\section{MATERIALS AND METHODS \\ Experimental vineyard}

The vineyard (about $1000 \mathrm{~m}^{2}$ ) is located in Shibajia village $\left(40^{\circ} 18^{\prime} 48^{\prime \prime} \mathrm{N}, 115^{\circ} 46^{\prime} 25^{\prime \prime} \mathrm{E}\right)$, Huailai County, Hebei Province in China. The vines of $V$. vinifera cv. Cabernet Sauvignon were planted in 2000 and grown on their own roots in an east-west row orientation. All the vines were spaced at $2.5 \mathrm{~m}$ $\times 0.5 \mathrm{~m}$ and trained to an upright cordon fan training system. The climate was characterised by distinctive seasons, with warm and humid summers and dry and cold winters. In detail, the climatic conditions from budburst to harvest in 2012 were $319.9 \mathrm{~mm}$ of accumulated rainfall, $1900 \mathrm{~h}$ of sunlight duration and a mean temperature of $18.9^{\circ} \mathrm{C}\left(12.9^{\circ} \mathrm{C}\right.$ mean minimum temperature and $25.3^{\circ} \mathrm{C}$ mean maximum temperature). With respect to the climatic conditions during grape development in 2013, the rainfall was $470.4 \mathrm{~mm}$, the sunshine hours were $1770 \mathrm{~h}$ and the mean temperature was $18^{\circ} \mathrm{C}$, with a mean minimum temperature of $12.5^{\circ} \mathrm{C}$ and a mean maximum temperature of $24.4^{\circ} \mathrm{C}$.

\section{Fruit sampling and sorting}

Approximately 80 vines in central rows were selected to harvest grapes on the basis of uniformity of vine growth, and the same plants were used in each year. The average yield in this vineyard was $3.05 \mathrm{~kg} /$ vine for 2012 and $2.57 \mathrm{~kg} /$ vine for 2013. Clusters were harvested and pooled from both sides of the canopy on 2012-10-07 and 2013-10-06. The pooled samples were divided into a control group $(\sim 30 \mathrm{~kg})$ and a treatment group $(\sim 150 \mathrm{~kg})$. The berries of the treatment group were separated from the pooled clusters, weighed and sorted into three categories based on a previous study (Roby et al., 2004): small ( $\leq 0.75 \mathrm{~g}$ ), medium (0.76 g to $1.25 \mathrm{~g})$ and large $(>1.25 \mathrm{~g})$. The sample-sorting procedure was completed within three days and, during the sorting process, the samples were stored in a refrigerated cabinet (about $5^{\circ} \mathrm{C}$ ). Triplicate 100-berry sub-samples of each size category were taken randomly for the measurement of skin weight and seed weight. Triplicate 100-berry sub-samples were taken to determine grape juice soluble solids ( ${ }^{\circ}$ Brix, TSS), pH, titratable acidity, tartaric acid and malic acid. Triplicate 200-berry sub-samples were frozen and used to determine total phenolics and anthocyanins. The remaining berries were used in the small-scale winemaking experiment. The berries of the control group were analysed identically to the treatment groups.

\section{Relative skin and seed mass}

Skins were gently removed from the berries and the seeds were separated from the remaining flesh. The sampled skins and seeds were washed in deionised water and carefully blotted with tissue paper to remove surface moisture. Skin and seed weights of each berry size category were measured one by one and independently.

\section{Small-scale winemaking}

For each berry size category, three lots of $4.0 \mathrm{~kg}$ berries per lot were crushed and transferred to $5 \mathrm{~L}$ fermentation containers. Each must was then sulphited with $60 \mathrm{mg} / \mathrm{L}$ of $\mathrm{SO}_{2}$, inoculated with $200 \mathrm{mg} / \mathrm{L}$ of hydrated commercial yeast (Fericru VR5, DSM, Netherlands), and controlled at $25 \pm 1^{\circ} \mathrm{C}$. All these ferments were controlled by measuring the temperature and the density of the must and plunged two or three times daily. After eight days of fermentation, the ferments were racked, the wet-solid were pressed, and the free-run and press wines were mixed. The malolactic fermentation was induced by inoculating with $10 \mathrm{mg} / \mathrm{L}$ malolactic bacteria (LALVIN 31, Lallemand, France) and keeping it at $20^{\circ} \mathrm{C}$ for two weeks. After that, the wines were re-sulphited with $50 \mathrm{mg} / \mathrm{L}$ of $\mathrm{SO}_{2}$ and cold stabilised for one month at $4{ }^{\circ} \mathrm{C}$. Finally, the wines were decanted, bottled and stored in an underground cellar with a constant temperature of $13^{\circ} \mathrm{C}$ to $14^{\circ} \mathrm{C}$ and a humidity of $60 \%$ to $70 \%$ for three months.

\section{Standard grape and wine analysis}

The analytical methods of the National Standard of the People's Republic of China (GB/T15038-2006) were used to determine the titratable acidity of the grapes and the residual sugar, ethanol and titratable acidity of the wines. TSS was measured using a pocket digital refractometer (PAL-1, Atago, Japan). The $\mathrm{pH}$ values were determined by a $\mathrm{pH}$ meter (PB10, Sartorius, Germany). The organic acid profiles of the grapes were determined using the HPLC method (Wen et al., 2014). All analyses were replicated twice for each sample. 


\section{Anthocyanins and total phenolics in grapes and wines}

Prior to total phenolic analysis, the skins of the grapes were peeled and ground into powder in liquid nitrogen. A total of $0.50 \mathrm{~g}$ of dry skin powder was immersed in $20 \mathrm{~mL}$ of methanol containing $2 \% \mathrm{HCl}$ and shaken in the dark at $25^{\circ} \mathrm{C}$ for $24 \mathrm{~h}$ at $150 \mathrm{rpm}$. The homogenate was centrifuged and the supernatant was collected. The wine samples were diluted 10-fold to ensure the absorbance at $765 \mathrm{~nm}$ was within the linear range of the spectrophotometer. Then the total phenolic content was determined according to the Folin-Ciocalteu colorimetric method and calculated as gallic acid equivalents (Singleton \& Rossi, 1965). All analyses were replicated twice independently.

The anthocyanins in the grape skins were extracted twice for each sample according to a previous method (He et al., 2010). Anthocyanins undergo a reversible structural transformation with a change in $\mathrm{pH}$ value. Briefly, the anthocyanins exist in the highly coloured oxonium or flavilium form at $\mathrm{pH} 1.0$, and in the colourless carbinol or hemiketal form at $\mathrm{pH}$ 4.5. Thus, the difference in absorbance at $520 \mathrm{~nm}$ is proportional to the concentration of anthocyanins. The total anthocyanin content could therefore be determined by the $\mathrm{pH}$ differential method and expressed as malvidin-3-O-glucoside equivalents (Fuleki \& Francis, 1968).

\section{Colour parameters of wines}

All wine samples were filtered through $0.45 \mu \mathrm{m}$ filters (cellulose acetate and nitrocellulose, MEMBRANA, Germany). Spectrophotometric measurements were carried out through a $0.2 \mathrm{~cm}$ path length at $420 \mathrm{~nm}, 520 \mathrm{~nm}$ and $620 \mathrm{~nm}$ on a T6 spectrophotometer (PGENERAL, China). Distilled water was used as the blank. The colour coordinates were calculated using CIELAB space (Ayala et al., 1997), including chroma $\left(C^{*}\right)$, hue $\left(h^{*}\right)$, red-greenness $\left(a^{*}\right)$, yellowblueness $\left(b^{*}\right)$, and lightness $\left(L^{*}\right)$. The colour intensity (CI) was estimated as the sum of absorbance at $420 \mathrm{~nm}, 520 \mathrm{~nm}$ and $620 \mathrm{~nm}$ (Glories, 1984). All analyses were replicated three times. In addition, the total colour difference $\left(\Delta \mathrm{E} a \mathrm{~b}^{*}\right)$ between two samples was obtained using the expression: $\Delta \mathrm{E} a \mathrm{~b}^{*}=\left[\left(\Delta \mathrm{L}^{*}\right)^{2}+\left(\Delta a^{*}\right)^{2}+\left(\Delta \mathrm{b}^{*}\right)^{2}\right]^{1 / 2}$ (Pérez-Magariño \& González-Sanjosé, 2003).

\section{Volatile compounds in wines}

Aromatic compounds from the wine samples were extracted by headspace solid-phase micro-extraction (HSSPME) equipped with a 50/30 $\mu \mathrm{m}$ DVB/CAR/PDMS fibre (Supelco, Bellefonte, PA., USA) and determined using gas chromatography (GC)/mass spectrometry (MS) in the laboratory according to a previously published method (Zhang et al., 2011). The GC-MS system used was an Agilent 6890 GC equipped with an Agilent 5975 mass spectrometer. The column used was a $60 \mathrm{~m} \times 0.25 \mathrm{~mm}$ HPINNOWAX capillary with $0.25 \mu \mathrm{m}$ film thickness ( $\& \mathrm{~W}$ Scientific, Folsom, USA). The flow rate of helium was 1 $\mathrm{mL} / \mathrm{min}$. The oven temperature was programmed as follows: $50^{\circ} \mathrm{C}$ held for $1 \mathrm{~min}$, increased to $220^{\circ} \mathrm{C}$ at a rate of $3^{\circ} \mathrm{C} / \mathrm{min}$, and held at $220^{\circ} \mathrm{C}$ for $5 \mathrm{~min}$. The mass spectrometer with the electron ionisation voltage at $70 \mathrm{eV}$ was scanned in the range of $\mathrm{m} / \mathrm{z} 30$ to 350 . Two replicates were conducted for each sample. The quantification procedure was carried out using the internal standard quantification method, based on prior studies (Zhang et al., 2011; Cai et al., 2014).

\section{Statistical analysis}

For each berry size category, the grape berries were divided into three parts, representing three biological repeats. The mean and standard error were calculated for all parameters, expect for the percentage distribution of berries. This was followed by one-way analysis of variance (ANOVA) using the Tukey test at a significance level of $\mathrm{p}<0.05$, using SPSS Statistics 20 (IBM, Chicago, USA).

\section{RESULTS AND DISCUSSION}

\section{The effects of berry size on fruit quality}

The chemical components in grape berries are mainly sugars, acids, phenolics and flavour compounds. Variation in berry size can change relative skin and seed proportions, and affect berry composition (Roby \& Matthews, 2004). As a result, heterogeneity sometimes poses considerable problems to the quality of grape berries and the final wines. Throughout the experiment, heterogeneity in the grapes was expressed in terms of variation in berry fresh weight. The distribution percentage of the berries into three weight categories (Table 1) was in accordance with the previously published Gaussian bell-shaped distribution of grape berries in different density or diameter classes (Rolle et al., 2012, 2015). The median-category berries were present in the highest frequency in the two growth seasons. Comparing the frequency distributions of berry mass and mean berry weight of each category, the berries in 2012 were smaller than those in 2013. An early water deficit resulted from low rainfall before véraison, which could reduce the rates of cell multiplication, and enlargement might help to explain this phenomenon (Ojeda et al., 2002; Roby \& Matthews, 2004).

The proportion of skin weight was about $13 \%$ to $18 \%$, and it decreased when berry size increased (Table 1). This result was supported by the theoretical relationship between berry surface and volume, as the ratio of berry surface to volume is equal to $3 /$ radius. Seeds accounted for $4 \%$ to $8 \%$ of total berry fresh weight, the proportion of which showed an increasing trend from the small to the large berry categories in both vintages (Table 1). Seed weight was strongly correlated with berry weight when expressed in seed mass per berry, due to the increase in seed number and seed size (Roby \& Matthews, 2004). These results are in accordance with previously reported data (Walker et al., 2005; Barbagallo et al., 2011; Gil et al., 2015). As for the relative skin mass and relative seed mass, both were lower in the grapes of 2013 than what was found in 2012. The former was probably due to the larger size of the berries in 2013, and the latter mainly resulted from the smaller number of seeds per berry in 2013, which we found in the current study. Causes for the small seed number in 2013 might connect with the impact of environmental factors or viticultural practices on pollination (Hardie \& Aggenbach, 1996; Keller, 2010). Furthermore, it is worth noting the anomalous result of relative skin mass and relative seed mass of the control in 2012, especially the latter, which was significantly lower than the other three groups. This phenomenon was mostly 
TABLE 1

Effect of berry size on the physical characteristics, standard parameters and chemical composition of the grapes.

\begin{tabular}{|c|c|c|c|c|c|}
\hline Parameter & Vintage & $\leq 0.75 \mathrm{~g}$ & $0.76-1.25 \mathrm{~g}$ & $>1.25 \mathrm{~g}$ & Control \\
\hline \multirow[t]{2}{*}{ Distribution percentage of berry mass $(\%)$} & 2012 & 19.8 & 63.7 & 16.5 & - \\
\hline & 2013 & 16.1 & 54.6 & 29.3 & - \\
\hline \multirow[t]{2}{*}{ Mean berry weight (g) } & 2012 & $0.59 \mathrm{a}$ & $0.99 \mathrm{c}$ & $1.36 \mathrm{~d}$ & $0.85 \mathrm{~b}$ \\
\hline & 2013 & $0.62 \mathrm{a}$ & $1.01 \mathrm{~b}$ & $1.51 \mathrm{c}$ & $1.04 \mathrm{~b}$ \\
\hline \multirow[t]{2}{*}{ Relative skin mass (\%) } & 2012 & $17.68 \mathrm{c}$ & $16.30 \mathrm{~b}$ & $15.61 \mathrm{a}$ & $15.98 \mathrm{a}$ \\
\hline & 2013 & $16.44 \mathrm{~b}$ & $13.54 \mathrm{a}$ & $13.14 \mathrm{a}$ & $13.81 \mathrm{a}$ \\
\hline \multirow[t]{2}{*}{ Relative seed mass $(\%)$} & 2012 & $6.35 \mathrm{ab}$ & $6.59 \mathrm{ab}$ & $7.85 \mathrm{~b}$ & $5.87 \mathrm{a}$ \\
\hline & 2013 & $4.01 \mathrm{a}$ & $4.64 \mathrm{ab}$ & $5.24 \mathrm{~b}$ & $4.70 \mathrm{ab}$ \\
\hline \multirow[t]{2}{*}{ Total soluble solids ( ${ }^{\circ}$ Brix) } & 2012 & $23.37 \mathrm{c}$ & $22.70 \mathrm{~b}$ & $22.07 \mathrm{a}$ & $22.57 \mathrm{~b}$ \\
\hline & 2013 & $21.97 \mathrm{~d}$ & $21.47 \mathrm{~b}$ & $20.93 \mathrm{a}$ & $21.60 \mathrm{c}$ \\
\hline \multirow[t]{2}{*}{$\mathrm{pH}$} & 2012 & $3.29 \mathrm{a}$ & $3.33 \mathrm{~b}$ & $3.42 \mathrm{c}$ & $3.26 \mathrm{a}$ \\
\hline & 2013 & $3.35 \mathrm{a}$ & $3.39 \mathrm{~b}$ & $3.47 \mathrm{~d}$ & $3.42 \mathrm{c}$ \\
\hline \multirow[t]{2}{*}{ Titratable acidity $(\mathrm{g} / \mathrm{L})^{\mathrm{a}}$} & 2012 & $8.68 \mathrm{~b}$ & $8.78 \mathrm{bc}$ & $8.47 \mathrm{a}$ & $9.14 \mathrm{c}$ \\
\hline & 2013 & $7.29 \mathrm{~b}$ & $7.29 \mathrm{~b}$ & $6.04 \mathrm{a}$ & $7.29 \mathrm{~b}$ \\
\hline \multirow[t]{2}{*}{ Malic acid $(\mathrm{mg} / \mathrm{g} \mathrm{FW})^{\mathrm{b}}$} & 2012 & $2.41 \mathrm{a}$ & $2.80 \mathrm{~b}$ & $2.96 \mathrm{~b}$ & $2.80 \mathrm{~b}$ \\
\hline & 2013 & $2.24 \mathrm{a}$ & $2.65 \mathrm{~b}$ & $3.29 \mathrm{c}$ & $2.81 \mathrm{~b}$ \\
\hline \multirow[t]{2}{*}{ Tartaric acid (mg/g FW) } & 2012 & $5.39 \mathrm{ab}$ & $5.12 \mathrm{a}$ & $5.59 \mathrm{~b}$ & $5.60 \mathrm{~b}$ \\
\hline & 2013 & $6.84 \mathrm{a}$ & $6.76 \mathrm{a}$ & $6.66 \mathrm{a}$ & $6.77 \mathrm{a}$ \\
\hline \multirow[t]{2}{*}{ Total phenolics (mg/g FW) } & 2012 & $1.72 \mathrm{~b}$ & $1.53 \mathrm{~b}$ & $0.90 \mathrm{a}$ & $1.17 \mathrm{a}$ \\
\hline & 2013 & $2.48 \mathrm{~b}$ & $1.22 \mathrm{a}$ & $1.21 \mathrm{a}$ & $1.24 \mathrm{a}$ \\
\hline \multirow[t]{2}{*}{ Anthocyanin (mg/g FW) } & 2012 & $2.24 \mathrm{a}$ & $2.06 \mathrm{a}$ & $1.78 \mathrm{a}$ & $2.20 \mathrm{a}$ \\
\hline & 2013 & $1.94 \mathrm{~d}$ & $1.04 \mathrm{c}$ & $0.9 \mathrm{a}$ & $0.98 \mathrm{~b}$ \\
\hline
\end{tabular}

a Titratable acidity was expressed as tartaric acid equivalents

${ }^{\mathrm{b}}$ Concentration expressed as mg per gram berry fresh weight $(\mathrm{mg} / \mathrm{g} \mathrm{FW})$

Different letters in the same row mean a significant difference $(\mathrm{p}<0.05)$

associated with 'millerandage', a potential viticultural problem in which grape bunches show the appearance of 'hens and chickens' (Keller, 2010). A number of shot berries with tiny or degenerated seeds in the control group might have led to the significantly lower relative seed mass of the control in 2012 (Keller, 2010).

In general, all grapes do not ripen homogeneously and berries with varying quality parameters coexist even in a same vineyard. The TSS in each berry is dependent upon berry size, exhibiting a negative function of berry weight (Table 1). The result here was in concurrence with previous reports (Roby et al., 2004; Barbagallo et al., 2011; Suklje et al., 2012). Previously, Petrie and Clingeleffer (2006) investigated the TSS distributions across berry populations on vines that had been thinned, and found that the TSS distributions were significantly skewed towards lower levels. The thinning treatment reduced vine vegetative growth and caused an increase in the content of berry soluble solids (Petrie \& Clingeleffer, 2006). It is worth noting that there also is a report showing no consistent trend between TSS and berry size (Walker et al., 2005). The $\mathrm{pH}$ showed the opposite trend compared with the TSS, and was positively related to berry weight (Table 1). The titratable acidity showed no consistent trend with berry size in 2012, while a decreasing trend was found in 2013. The anomalous results for $\mathrm{pH}$ and titratable acidity in the control of 2012, where $\mathrm{pH}$ was lower than any of the berry size classes and titratable acidity was higher than other berry classes, were probably due to the aforementioned 'millerandage', since unripe shot berries contain more acid (Keller, 2010). Comparing the vintages, grape berries in 2012 were characterised by higher TSS, reaching a greater level of maturity, as a result of longer sunshine hours and lower rainfall in 2012.

The composition of organic acids is another crucial trait that determines the acidity of the wine. The tartaric acid and malic acid account for $90 \%$ of the total acids in the grape berries (Sabir et al., 2010). Previously, Walker et al. (2005) reported no significant effect of berry mass on juice tartaric acid concentrations, but the skin tartaric acid concentrations decreased with increasing berry mass. In Table 1, the tartaric 
acid concentration of the whole berry shows no consistent trend with berry size, while the malic acid exhibited a positive function of berry size. In 2012, the concentration of tartaric acid was highest in the largest berry mass categories, whereas, in 2013, the tartaric acid decreased slightly when the berry size increased, without significant differences.

The phenolic composition of grapes is closely related to wine sensory characteristics. Specifically, the anthocyanins originating in the grape skins are largely related to wine appearance, and other phenolic compounds, such as flavonols and flavan-3-ols, which accumulate mainly in the skins and seeds, are closely correlated with the mouthfeel of wines (Boulton, 2001; Ribéreau-Gayon et al., 2006). So the concentrations of anthocyanin and total phenolics in grapes is a function of relative skin mass and undoubtedly related to the berry size. The results here show an inverse relationship between total phenolics and berry mass (Table 1). The total phenolic concentration in the small berries was nearly twice that in the large berries. The concentration of anthocyanin was also dependent upon the berry size. The tendencies were the same in both years, but in 2012 the concentrations declined slightly, but not significantly, when the berry size increased, while in 2013 the concentrations were negatively and significantly affected by the berry size. A higher ratio of skin to mass in the smaller berries was supposed to be the reason (Ojeda et al., 2002). Additionally, the higher sugar levels in small berries could also stimulate the accumulation of anthocyanins (Dai et al., 2014; Wong et al., 2016). The quantity of anthocyanin was positively correlated with berry size when expressed in $\mathrm{mg} /$ berry $(\mathrm{mg} / \mathrm{g}$ fresh weight $\times$ berry size). Total phenolics or anthocyanins per berry increased less than proportionally to the berry fresh weight, resulting in the relative concentrations of total phenolics or anthocyanins being lower in the larger berries, which is in agreement with previous results (Roby et al., 2004; Barbagallo et al., 2011; Wong et al., 2016). Furthermore, the concentrations of total phenolics and anthocyanins were also significantly affected by vintage. However, in this study, total phenolics showed no consistent variation in the two consecutive years among these berry size categories. The anthocyanin concentrations were much higher in 2012 than in 2013, parallel to the grape maturity in the two years.

As mentioned above, many biotic and abiotic factors determined the final berry size. Thus, the composition of grape berries is not dependent in a simple way on the berry mass, since the ways leading to berry size variation play more important roles in determining berry composition than the berry size per se (Walker et al., 2005; Matthews \& Nuzzo, 2007; Holt et al., 2008). Moreover, the environmental and cultural practices that give rise to variation in berry size could induce changes in fruit composition, and these influences are largely independent of the variation in berry size (Roby et al., 2004). In the present study, the berry size heterogeneity resulting from natural variation also affected the fruit composition. The smaller berries showed higher TSS and total phenolics, while the larger berries exhibited higher titratable acidity and malic acid. These results indicate that berry size alone also relates to fruit quality.

Besides the heterogeneity in berry weight, many reports have surveyed the variability in density (Kontoudakis et al.,
2011) and TSS (Šuklje et al., 2012), and have confirmed that the heterogeneity was present throughout the whole ripening process (Rolle et al., 2012, 2015). In general, berry size increased with a decrease in density. The higher/lower berry densities were always associated with smaller/larger berries of 'Nebbiolo' grapes (Rolle et al., 2012). Berries of the same diameter or weight could have different TSS levels, in other words different physiological ripening levels (Šuklje et al., 2013). While grape heterogeneity causes uniformity in berry maturity due to the potentially unripe grapes hidden within the cluster or overripe grapes exposed to sunlight, many winemakers are of the view that heterogeneity sometimes adds complexity to wines and needs further research (Robinson, 2006; Melo et al., 2015).

\section{The effects of berry size on wine quality}

Berry size is an important factor in the quantity and quality of the final wine (Walker et al., 2005; Holt et al., 2008; Melo et al., 2015). In order to improve this understanding, the relationships between berry size and basic indices, colour parameters, total anthocyanins, total phenolics and volatile compounds in the wines were determined. Table 2 shows the routine parameters of these sampled wines. The degree of residual sugar and alcohol were positively linked with TSS in both years, therefore exhibiting a decline against the increased berry size. The $\mathrm{pH}$ value was the highest in the large category, and the titratable acidity showed the highest content in the medium category. Taking the vintage into consideration, the acidity was $0.7 \mathrm{~g}$ to $1.9 \mathrm{~g}$ tartaric acid/L higher in 2013 , and the $\mathrm{pH}$ value was about 0.2 to 0.3 lower in 2013. The alcohol was about $0.5^{\circ}$ higher in 2012 than that in 2013 for each size category. These differences confirm that the heterogeneity in berry size could affect the final wines' composition.

The quality and stability of colour are important wine attributes. Table 2 also shows the colour characteristics of the wines in the two years. The berry size and vintage appeared to have a significant correlation with the colour parameters. Specifically, the value of $L^{*}$ had a positive relationship with the berry size, but other parameters, such as CI, $C^{*}$, $h^{*}, a^{*}$ and $b^{*}$, all showed opposite tendencies. The results here were approaching that of previously reported data, in which CI, $C^{*}, h^{*}$ decreased and $L^{*}$ increased when the berry size increased (Gil et al., 2015), or when the berry density decreased (Kontoudakis et al., 2011). These parameters indicate that smaller berries have the potential to produce wines with a darker and more saturated colour. It is worth noting that the lower $\mathrm{pH}$ of wines made from small berries also contributed partly to the darker colour compared to other categories. Chromatic differences between wines were also calculated (Table 3 ). It was generally accepted that the human eye could distinguish a pair of wines when the chromatic difference was greater than five units (PérezMagariño \& González-Sanjosé, 2003). For each vintage, only wines made from the large berries showed the $\Delta \mathrm{E} a b^{*}$ $\geq 5$ when compared with other categories. Therefore, the existing colour differences amongst wines made with large berries and other categories of berry size were sufficient enough to be distinguished. In addition, the wines of 2012 presented higher CI, $C^{*}$ and $a^{*}$ and lower $h^{*}, L^{*}$ and $b^{*}$ than 
those of 2013. The wines made from the same sized berries in the two years had even higher $\Delta \mathrm{E} a b^{*}$ differences than 5 . This suggests that the vintage also had a great influence on wine colour, due to the complicated effects of climate on the grape maturity indicators (Kontoudakis et al., 2011).

The phenolic maturity of the grapes is responsible for the quality of red wine, affecting its colour, body and structure (Boulton, 2001; Ribéreau-Gayon et al., 2006). In our study,

TABLE 2

Effect of berry size on routine parameters, colour characteristics and phenolic compounds in the wines.

\begin{tabular}{|c|c|c|c|c|c|}
\hline Parameter & Vintage & $\leq 0.75 \mathrm{~g}$ & $0.76-1.25 \mathrm{~g}$ & $>1.25 \mathrm{~g}$ & control \\
\hline \multirow[t]{2}{*}{ Total sugar $(\mathrm{g} / \mathrm{L})^{\mathrm{a}}$} & 2012 & $2.97 \mathrm{~d}$ & $2.75 \mathrm{c}$ & $2.65 \mathrm{a}$ & $2.85 \mathrm{~b}$ \\
\hline & 2013 & $2.88 \mathrm{c}$ & $2.75 \mathrm{~b}$ & $2.65 \mathrm{a}$ & $2.85 \mathrm{c}$ \\
\hline \multirow[t]{2}{*}{$\mathrm{pH}$} & 2012 & $3.73 \mathrm{a}$ & $3.72 \mathrm{a}$ & $3.89 \mathrm{~b}$ & $3.71 \mathrm{a}$ \\
\hline & 2013 & $3.44 \mathrm{a}$ & $3.50 \mathrm{~b}$ & $3.57 \mathrm{c}$ & $3.51 \mathrm{~b}$ \\
\hline \multirow[t]{2}{*}{ Titratable acidity $(\mathrm{g} / \mathrm{L})^{\mathrm{b}}$} & 2012 & $6.72 \mathrm{a}$ & $7.31 \mathrm{~b}$ & $6.90 \mathrm{a}$ & $7.02 \mathrm{ab}$ \\
\hline & 2013 & $8.60 \mathrm{~b}$ & $8.62 \mathrm{~b}$ & $7.68 \mathrm{a}$ & $8.68 \mathrm{~b}$ \\
\hline \multirow[t]{2}{*}{ Alcohol degree (\% vol) } & 2012 & $12.87 \mathrm{c}$ & $12.44 \mathrm{~b}$ & $12.13 \mathrm{a}$ & $12.44 \mathrm{~b}$ \\
\hline & 2013 & $11.91 \mathrm{~b}$ & $11.91 \mathrm{~b}$ & $11.64 \mathrm{a}$ & $11.93 \mathrm{~b}$ \\
\hline \multirow[t]{2}{*}{$\mathrm{CI}$} & 2012 & $1.10 \mathrm{~b}$ & $1.03 \mathrm{~b}$ & $0.85 \mathrm{a}$ & $1.02 \mathrm{~b}$ \\
\hline & 2013 & $0.84 \mathrm{c}$ & $0.82 \mathrm{c}$ & $0.67 \mathrm{a}$ & $0.78 \mathrm{~b}$ \\
\hline \multirow[t]{2}{*}{$C^{*}$} & 2012 & $41.70 \mathrm{~b}$ & $39.91 \mathrm{~b}$ & $33.63 \mathrm{a}$ & $39.63 \mathrm{~b}$ \\
\hline & 2013 & $31.98 \mathrm{c}$ & $30.85 \mathrm{~b}$ & $25.60 \mathrm{a}$ & $30.07 \mathrm{~b}$ \\
\hline \multirow[t]{2}{*}{$h^{*}$} & 2012 & $4.50 \mathrm{~d}$ & $3.41 \mathrm{~b}$ & $2.63 \mathrm{a}$ & $3.98 \mathrm{c}$ \\
\hline & 2013 & $12.45 \mathrm{~b}$ & $12.53 \mathrm{~b}$ & $11.83 \mathrm{a}$ & $12.55 \mathrm{~b}$ \\
\hline \multirow[t]{2}{*}{$L^{*}$} & 2012 & $72.56 \mathrm{a}$ & $73.83 \mathrm{a}$ & $77.39 \mathrm{~b}$ & $74.00 \mathrm{a}$ \\
\hline & 2013 & $75.66 \mathrm{a}$ & $76.13 \mathrm{a}$ & $80.02 \mathrm{c}$ & $77.31 \mathrm{~b}$ \\
\hline \multirow[t]{2}{*}{$a^{*}$} & 2012 & $41.57 \mathrm{~b}$ & $39.85 \mathrm{~b}$ & $33.6 \mathrm{a}$ & $39.54 \mathrm{~b}$ \\
\hline & 2013 & $31.23 \mathrm{~d}$ & $30.11 \mathrm{c}$ & $25.05 \mathrm{a}$ & $29.35 \mathrm{~b}$ \\
\hline \multirow[t]{2}{*}{$b^{*}$} & 2012 & $3.28 \mathrm{~d}$ & $2.37 \mathrm{~b}$ & $1.56 \mathrm{a}$ & $2.74 \mathrm{c}$ \\
\hline & 2013 & $6.88 \mathrm{c}$ & $6.72 \mathrm{bc}$ & $5.25 \mathrm{a}$ & $6.54 \mathrm{~b}$ \\
\hline \multirow[t]{2}{*}{ Total phenolics (mg/L) } & 2012 & $1454.7 \mathrm{a}$ & $1468.3 \mathrm{a}$ & 1418.9 a & $1417.0 \mathrm{a}$ \\
\hline & 2013 & $820.7 \mathrm{a}$ & $840.8 \mathrm{a}$ & $806.6 \mathrm{a}$ & $827.7 \mathrm{a}$ \\
\hline \multirow[t]{2}{*}{ Anthocyanin (mg/L) } & 2012 & $315.4 \mathrm{~b}$ & $318.2 \mathrm{~b}$ & $274.2 \mathrm{a}$ & $297.7 \mathrm{~b}$ \\
\hline & 2013 & $243.7 \mathrm{~b}$ & $257.1 \mathrm{c}$ & $227.5 \mathrm{a}$ & $247.7 \mathrm{~b}$ \\
\hline
\end{tabular}

${ }^{a}$ Concentration represented by glucose

${ }^{\mathrm{b}}$ Concentration expressed as tartaric acid equivalents

Different letters in the same row mean a significant difference $(\mathrm{p}<0.05)$

TABLE 3

Total colour differences $\left(\Delta \mathrm{Eab}^{*}\right)^{\mathrm{a}}$ amongst wines from the two vintages.

\begin{tabular}{lcccc}
\hline Category & $\leq 0.75 \mathrm{~g}$ & $0.76-1.25 \mathrm{~g}$ & $>1.25 \mathrm{~g}$ & $\mathrm{c}$ \\
\hline$\leq 0.75 \mathrm{~g}$ & $\mathbf{1 1 . 3 7}$ & 1.23 & 7.73 & 2.52 \\
$0.76-1.25 \mathrm{~g}$ & 2.31 & $\mathbf{1 0 . 9 1}$ & 6.54 & 1.41 \\
$>1.25 \mathrm{~g}$ & 9.47 & 7.24 & $\mathbf{9 . 6 7}$ & 5.24 \\
control & 2.54 & 0.50 & 6.94 & $\mathbf{1 1 . 3 6}$ \\
\hline
\end{tabular}

${ }^{\text {a }}$ Values in the diagonal line (bold) correspond to colour differences between 2012 and 2013 . Values below the diagonal correspond to the 2012 vintage. Values above the diagonal correspond to the 2013 vintage 
parallel to the results of grape maturity and wine colour, the total phenolic and anthocyanin contents in 2012 were higher than in 2013 (Table 2). Total phenolics were slightly but not significantly higher in medium-category wines than in others in both vintages. The anthocyanin concentrations also showed similar tendencies. But the concentration was significantly higher in the medium category than in the large category. The influence of berry size on phenolic compounds might be completed through variations in the relative skin and seed mass. The effect of the addition of pomace to or the removal thereof from red grapes before fermentation on wine colour and phenolic composition has been well documented (Canals et al., 2008; Gordillo et al., 2014). At the superficial level, the wines made from the smaller berries with a higher proportion of skin to berry weight should have a higher concentration of anthocyanin, as has been reported on the higher anthocyanins in denser/smaller grapes (Kontoudakis et al., 2011; Rolle et al., 2015). In the present study, the content of anthocyanin in wines obtained from the small berries was lower than that made with the medium berries. These results are consistent with previously published data (Gordillo et al., 2014), in which a further addition of pomace to wines led to a lower anthocyanin content. The loss of anthocyanins was suggested to be due to the adsorption of pigments by the extra amounts of skins and seeds, the decrease in co-pigmentation, and the formation of polymeric pigments during wine maturation (Boulton, 2001; Gordillo et al., 2014). Similarly, anthocyanins in the wines from the large category were lower than in the others, which was mainly due to the lower anthocyanin content in the skins; the lower anthocyanin extractability resulted from the lower ethanol content and higher $\mathrm{pH}$ value (Canals et al., 2005). Parallel to this, wine colour was affected accordingly, as anthocyanins and polyphenols were closely correlated with the coloration, co-pigmentation and polymerisation (Boulton, 2001).

\section{The effects of berry size on volatile compounds of the wines}

The aroma and flavour are other important characteristics that define the specific wine style produced. Volatile compounds play a vital role in the quality of wine, as a consequence of their pronounced sensory stimulus (Kalua \& Boss, 2009). The result here show that some of the volatiles exhibited significant differences between berries from different size categories (Table 4).

Five C6 alcohols were identified in both vintages, viz. 1-hexanol, (E)-3-hexen-1-ol, (Z)-3-hexen-1-ol, (E)-2hexen-1-ol and (Z)-2-hexen-1-ol, which contributed to the herbaceous or grassy aroma of the wines (Peinado et al., 2004). The C6 alcohols in the wines were dominated by 1-hexanol, accounting for more than $97 \%$, which showed a negative relationship with berry size. The reason for this was presumed to be a higher relative skin mass, which increased the amount of green leaf volatiles in smaller berries, with a stronger effect of skin contact during fermentation (Selli et al., 2003; Callejón et al., 2012). Moreover, Wong et al. (2016) reported the stronger upregulation of genes encoding alcohol dehydrogenases in small versus large berries, which might also contribute to a higher production of C6 compounds in smaller berries. The content of C6 alcohols showed higher levels in 2012 than in 2013, in accordance with the higher ripeness of the harvested grapes (Kalua \& Boss, 2009). This result is interesting because these compounds are generally known to bring the green/grassy aromas that are perceived in wines from early maturity grapes. The distribution of volatile compounds in the skin and pulp of Cabernet Sauvignon was studied previously, and it was found that more abundant $\mathrm{C} 6$ compounds, such as hexanal and hexanol, were distributed in the skins (Gomez et al., 1994). The higher relative skin mass of the berries in 2012 contributed partly to the higher 1-hexanol. Furthermore, the effect of skin contact also increased the hexanol contents (Selli et al., 2003).

Higher alcohols were the most abundant secondary metabolites produced during alcoholic fermentation (Swiegers \& Pretorius, 2005). Quantitatively, isobutanol, isopentanol and laevo-2,3-butanediol constituted the majority of higher alcohols in the wines. There was a significant effect on the content of laevo-2,3-butanediol in both seasons, with smaller berries having higher levels, whereas other higher alcohols showed no consistent trend in the two vintages. The results here show that berry size has a limited effect on the higher alcohols. However, the vintage showed a large seasonal difference, which might be due to the variation in ripeness between 2012 and 2013, since the content of higher alcohols increased in the wines as ripening progressed (Bindon et al., 2013). Esters were another major volatile compound, which endow fruity flavour to wines, and were composed primarily of fatty acid ethyl esters and acetate esters (Swiegers \& Pretorius, 2005). In the present study, most esters showed no significant differences among different sized categories. Only ethyl lactate showed a consistent increment with increasing berry size in both years. The ethyl lactate showed the highest concentration in wines made from large berries. Acids also played an important role in the complexity of the wine bouquet and contributed to the synthesis of esters (Swiegers \& Pretorius, 2005). Among the volatile acids detected in the present study, acetic acid was significantly higher in wine from small berries than in the other wines in 2013, while isovaleric acid showed a similar trend only in 2012. Carbonyl compounds were also metabolised during fermentation. The wines from the large berries had higher concentrations of acetoin, octanal and 2,3-butanedione than wines from both the small and medium berries in 2012. The content of 2,3-butanedione was around 1.5 to $2.0 \mathrm{mg} / \mathrm{L}$ and could contribute a desirable 'buttery' flavour. The lack of 2,3-butanedione and substantially lower content of acetoin in 2013 were supposed to be caused during malolactic fermentation (Swiegers \& Pretorius, 2005).

Terpenoids, which are aroma substances synthesised in the grapes, play important roles in the 'varietal aroma' of wines. Three terpenes, namely citronellol, trans-nerolidol and farnesol, showed a significant impact of berry size only in 2012. The concentrations of citronellol and transnerolidol were significantly higher in the large berry category, while the farnesol showed the highest level in the small berry category. $\beta$-ionone was present in the wines at a very low concentration, but was characterised as an important fragrance because of its very low sensory threshold (Swiegers \& Pretorius, 2005). The concentration of $\beta$-ionone 
was significantly higher in the small berry category in 2013 compared to the other berries, contributing more flower and fruit notes to wines made from small berries (Ferreira et al., 2000). Methoxypyrazines are important markers to assess the aromatic quality of Cabernet Sauvignon wines. The most important pyrazine found in Cabernet Sauvignon grapes and wines is 3-isobutyl-2-methoxypyrazine (IBMP), which contributes to green pepper and musty aromas (Dunlevy et al., 2013). The berry size had a positive and significant influence on the level of IBMP in the wines of 2013, while

TABLE 4

Volatile compounds $(\mu \mathrm{g} / \mathrm{L}$, mean $\pm \mathrm{SD})$ in the respective wines made from the different sized berries.

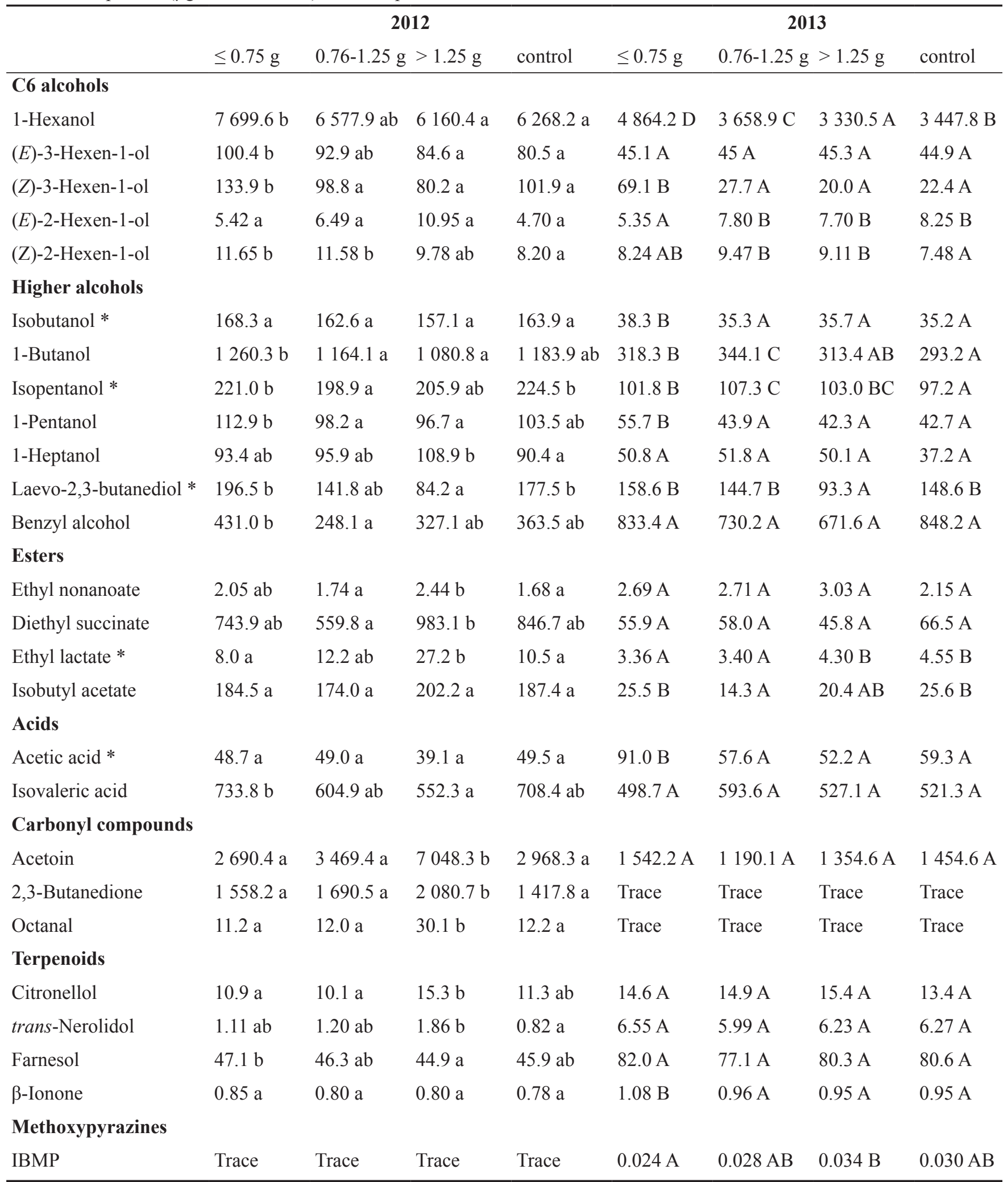

* indicates that the concentration unit is $\mathrm{mg} / \mathrm{L}$; Different letters in the same row mean a significant difference $(\mathrm{p}<0.05)$. 
only trace amounts of IBMP were found in the wines of 2012. The variation in ripeness (TSS) contributed to this seasonal difference, since IBMP consistently decreases during grape ripening (Bindon et al., 2013).

In summary, the wines made in 2012 contained more abundant esters, alcohols and carbonyl compounds, whereas the wines of 2013 had higher levels of acids and pyrazines. Most volatile compounds showed no consistent trend in the two years, and most of the trends affected by berry size were not significant. This lack of impact, however, is interesting. In addition, there are also some interesting results for 1-hexanol and laevo-2,3-butanediol, because they are the only consistent and significant trends across the vintages for wine volatiles. These two compounds showed the highest levels in wines made with small grapes, and endowed green/grassy aromas and lactic/buttery notes to the wines respectively. However, not all volatile compounds contributed equally to wine aroma; the contribution of each compound depended on its concentration/threshold ratio, known as the 'odour activity value' (Peinado et al., 2004). Meanwhile, the aroma perceived by the taster was the consequence of the complicated sensory contributions of various volatiles and could rarely be attributed to a simple mixture of those compounds (Peinado et al., 2004).

\section{CONCLUSIONS}

Relationships between berry size, grape composition and the resulting wine quality were determined on the ripe fruit of 'Cabernet Sauvignon'. In the range of berry sizes studied here, the small berries were associated with higher titratable acidity, lower $\mathrm{pH}$ and a higher proportion of skin mass, and certainly accumulated more anthocyanin and total phenolics. However, variations in anthocyanins and total phenolics of the wines were not reflected in changes in the characteristics of the berry. The wine obtained from the medium berries showed the highest concentrations of anthocyanin and total phenolics, whereas the wine made from the small berries exhibited the deepest colour. Furthermore, berry size had a limited effect on wine volatiles. Only 1-hexanol and laevo2,3-butanediol showed consistent and significant trends across vintages, which were negatively correlated with berry size.

\section{LITERATURE CITED}

Ayala, F., Echavarri, J.F. \& Negueruela, A.I., 1997. A new simplified method for measuring the color of wines. 1. Red and rose wines. Am. J. Enol. Vitic. 48(3), 357-363

Barbagallo, M.G., Guidoni, S. \& Hunter, J.J., 2011. Berry size and qualitative characteristics of Vitis vinifera L. cv. Syrah. S. Afr. J. Enol. Vitic. 32(1), 129-136

Bindon, K., Varela, C., Kennedy, J., Holt, H. \& Herderich, M., 2013 Relationships between harvest time and wine composition in Vitis vinifera L. cv. Cabernet Sauvignon 1. Grape and Wine Chemistry. Food Chem. 138(2), 1696-1705.

Boulton, R., 2001. The copigmentation of anthocyanins and its role in the color of red wine: A critical review. Am. J. Enol. Vitic. 52, 67-87.

Bravdo, B., Hepner, Y., Loinger, C., Cohen, S. \& Tabacman, H., 1985. Effect of irrigation and crop level on growth, yield and wine quality of cv. Cabernet sauvignon. Am. J. Enol. Vitic. 36, 132-139.
Cai, J., Zhu, B.Q., Wang, Y.H., Lu, L., Lan, Y.B., Reeves, M.J. \& Duan, C.Q., 2014. Influence of pre-fermentation cold maceration treatment on aroma compounds of Cabernet Sauvignon wines fermented in different industrial scale fermenters. Food Chem. 154, 217-229.

Callejón, R.M., Margulies, B., Hirson, G.D. \& Ebeler, S.E., 2012. Dynamic changes in volatile compounds during the fermentation of Cabernet Sauvignon grapes with and without skins. Am. J. Enol. Vitic. 63(3), 301312.

Canals, R., Llaudy, M.C., Canals, J.M. \& Zamora, F., 2008. Influence of the elimination and addition of seeds on the colour, phenolic composition and astringency of red wine. Eur. Food Res. Technol. 226(5), 1183-1190.

Canals, R., Llaudy, M.C., Valls, J., Canals, J.M. \& Zamora, F., 2005. Influence of ethanol concentration on the extraction of colour and phenolic compounds from the skin and seeds of Tempranillo grapes at different stages of ripening. J. Agric. Food Chem. 53, 4019-4025.

Cooley, N.M., Clingeleffer, P.R. \& Walker, R.R., 2017. Effect of water deficits and season on berry development and composition of Cabernet Sauvignon (Vitis vinifera L.) grown in a hot climate. Aust. J. Grape Wine Res. 23(2), 260-272.

Dai, Z.W., Meddar, M., Renaud, C., Merlin, I., Hilbert, G., Delrot, S. \& Gomès, E., 2014. Long-term in vitro culture of grape berries and its application to assess the effects of sugar supply on anthocyanin accumulation. J. Exp. Bot. 65(16), 4665-4677.

Dokoozlian, N.K. \& Kliewer, W.M., 1996. Influence of light on grape berry growth and composition varies during fruit development. J. Am. Soc. Hortic. Sci. 121(5), 869-874.

Dunlevy, J.D., Dennis, E.G., Soole, K.L., Perkins, M.V., Davies, C. \& Boss, P.K., 2013. A methyltransferase essential for the methoxypyrazine $\square$ derived flavour of wine. Plant J. 75(4), 606-617.

Fernandez, L., Pradal, M., Lopez, G., Berud, F., Romieu, C. \& Torregrosa, L., 2006. Berry size variability in Vitis vinifera L. Vitis 45(2), 53-55.

Ferreira, V., López, R. \& Cacho, J.F., 2000. Quantitative determination of the odorants of young red wines from different grape varieties. J. Sci. Food Agric. 80(11), 1659-1667.

Fuleki, T. \& Francis, F.J., 1968. Quantitative methods for anthocyanins. 2. Determination of total anthocyanin and degradation index for cranberry Juice. J. Food Sci. 33, 78-82.

Gil, M., Pascual, O., Gómez-Alonso, S., García-Romero, E., HermosínGutiérrez, I., Zamora, F. \& Canals, J.M., 2015. Influence of berry size on red wine colour and composition. Aust. J. Grape Wine Res. 21(2), 200-212.

Glories, Y., 1984. La couleur des vins rouges. 1e. Partie: Les équilibres des anthocyanes et des tannins. Connaissances de la Vigne et du Vin, 18, 195217.

Gomez, E., Martinez, A. \& Laencina, J., 1994. Localization of free and bound aromatic compounds among skin, juice and pulp fractions of some grape varieties. Vitis 33(1), 1-4

Gordillo, B., Cejudo-Bastante, M.J., Rodríguez-Pulido, F.J., Jara-Palacios, M.J., Ramírez-Perez, P., Gonzalez-Miret, M.L. \& Heredia, F.J., 2014. Impact of adding white pomace to red grapes on the phenolic composition and color stability of Syrah wines from a warm climate. J. Agric. Food Chem. 62(12), 2663-2671.

Hardie, W.J. \& Aggenbach, S.J., 1996. Effects of site, season and viticultural practices on grape seed development. Aust. J. Grape Wine Res. 2(1), 1-4.

He, J.J., Liu, Y.X., Pan, Q.H., Cui, X.Y. \& Duan, C.Q., 2010. Different anthocyanin profiles of the skin and the pulp of Yan73 (Muscat Hamburg $\times$ Alicante Bouschet) grape berries. Molecules 15, 1141-1153. 
Holt, H.E., Francis, I.L., Field, J., Herderich, M.J. \& Iland, P.G., 2008. Relationships between berry size, berry phenolic composition and wine quality scores for Cabernet Sauvignon (Vitis vinifera L.) from different pruning treatments and different vintages. Aust. J. Grape Wine Res. 14(3), 191-202.

Houel, C., Martin-Magniette, M.L., Nicolas, S.D., Lacombe, T., Le-Cunff, L., Franck, D., Torregrosa, L., Conéjéro, G., Lalet, S., This, P. \& AdamBlondon, A.F., 2013. Genetic variability of berry size in the grapevine (Vitis vinifera L.). Aust. J. Grape Wine Res. 19(2), 208-220.

Kalua, C.M. \& Boss, P.K., 2009. Evolution of volatile compounds during the development of Cabernet Sauvignon grapes (Vitis vinifera L.). J. Agric. Food Chem. 57(9), 3818-3830.

Keller, M., 2010 ( $1^{\text {st }}$ ed.). The science of grapevines: Anatomy and physiology. Elsevier Academic Press, Burlington, MA.

Keller, M., Mills, L.J. \& Harbertson, J.F., 2011. Rootstock effects on deficitirrigated winegrapes in a dry climate: Vigor, yield formation, and fruit ripening. Am. J. Enol. Vitic. 63(1), 29-39.

Kennedy, J.A., Matthews, M.A. \& Waterhouse, A.L., 2002. Effect of maturity and vine water status on grape skin and wine flavonoids. Am. J. Enol. Vitic. 53(4), 268-274.

Kontoudakis, N., Esteruelas, M., Fort, F., Canals, J.M., De Freitas, V. \& Zamora, F., 2011. Influence of the heterogeneity of grape phenolic maturity on wine composition and quality. Food Chem. 124(3), 767-774.

Matthews, M.A. \& Anderson, M.M., 1988. Fruit ripening in Vitis vinifera L.: Response to seasonal water deficits. Am. J. Enol. Vitic. 39(4), 313-320.

Melo, M.S., Schultz, H.R., Volschenk, C.G. \& Hunter, J.J., 2015. Berry size variation of Vitis vinifera L. cv. Syrah: Morphological dimensions, berry composition and wine quality. S. Afr. J. Enol. Vitic. 36(1), 1-10.

Ojeda, H., Andary, C., Kraeva, E., Carbonneau, A. \& Deloire, A., 2002. Influence of pre- and postveraison water deficit on synthesis and concentration of skin phenolic compounds during berry growth of Vitis vinifera cv. Shiraz. Am. J. Enol. Vitic. 53(4), 261-267.

Peinado, R.A., Moreno, J., Bueno, J.E., Moreno, J.A. \& Mauricio, J.C., 2004. Comparative study of aromatic compounds in two young white wines subjected to pre-fermentative cryomaceration. Food Chem. 84(4), 585-590.

Pérez-Magariño, S. \& González-Sanjosé, M.L., 2003. Application of absorbance values used in wineries for estimating CIELAB parameters in red wines. Food Chem. 81(2), 301-306

Petrie, P.R. \& Clingeleffer, P.R., 2006. Crop thinning (hand versus mechanical), grape maturity and anthocyanin concentration: Outcomes from irrigated Cabernet Sauvignon (Vitis vinifera L.) in a warm climate. Aust. J. Grape Wine Res. 12(1), 21-29.

Pisciotta, A., Di Lorenzo, R., Barbagallo, M.G. \& Hunter, J.J., 2013. Berry characterisation of cv. Shiraz according to position on the rachis. S. Afr. J. Enol. Vitic. 34(1), 100-107.

Ribéreau-Gayon, P., Glories, Y., Maujean, A. \& Dubourdieu, D., 2006. Phenolic compounds. In Handbook of enology, vol. 2. Wiley, Chichester.

Robinson, J., 2006 ( $3^{\text {rd }}$ ed.). The Oxford companion to wine. Oxford, Oxford University Press.

Roby, G. \& Matthews, M., 2004. Relative proportions of seed, skin and flesh, in ripe berries from Cabernet Sauvignon grapevines grown in a vineyard either well irrigated or under water deficit. Aust. J. Grape Wine Res. 10(1), 74-82.
Roby, G., Harbertson, J.F., Adams, D.A. \& Matthews, M.A., 2004. Berry size and vine water deficits as factors in winegrape composition: anthocyanins and tannins. Aust. J. Grape Wine Res. 10(2), 100-107.

Rolle, L., Torchio, F., Giacosa, S. \& Río Segade, S., 2015. Berry density and size as factors related to the physicochemical characteristics of Muscat Hamburg table grapes (Vitis vinifera L.). Food Chem. 173, 105-113.

Rolle, L., Torchio, F., Giacosa, S., Río Segade, S., Cagnasso, E. \& Gerbi, V., 2012. Assessment of physicochemical differences in Nebbiolo grape berries from different production areas and sorted by flotation. Am. J. Enol. Vitic. 62(2), 195-204.

Sabir, A., Kafkas, E. \& Tangolar, S., 2010. Distribution of major sugars, acids, and total phenols in juice of five grapevine (Vitis spp.) cultivars at different stages of berry development. Span. J. Agric. Res. 8(2), 425-433.

Selli, S., Cabaroglu, T., Canbas, A., Erten, H. \& Nurgel, C., 2003. Effect of skin contact on the aroma composition of the musts of Vitis vinifera $\mathrm{L}$. cv. Muscat of Bornova and Narince grown in Turkey. Food Chem. 81(3), 341-347.

Shellie, K.C., 2010. Water deficit effect on ratio of seed to berry fresh weight and berry weight uniformity in winegrape cv. Merlot. Am. J. Enol. Vitic. 61(3), 414-418.

Singleton, V.L., 1972. Effects on red wine composition of removing juice before fermentation to simulate variation in berry size. Am. J. Enol. Vitic. 23(3), 106-113.

Singleton, V.L. \& Rossi, J.A., 1965. Colorimetry of total phenolics with phosphomolybdic- phosphotungstic acid reagents. Am. J. Enol. Vitic. 16, 144-158.

Smart, R.E., Dick, J.K., Gravett, I.M. \& Fisher, B.M., 2017. Canopy management to improve grape yield and wine quality-principles and practices. S. Afr. J. Enol. Vitic. 11(1), 3-17.

Šuklje, K., Lisjak, K., Baša Česnik, H., Janeš, L., Du Toit, W., Coetzee, Z., Vanzo, A. \& Deloire, A., 2012. Classification of grape berries according to diameter and total soluble solids to study the effect of light and temperature on methoxypyrazine, glutathione, and hydroxycinnamate evolution during ripening of Sauvignon Blanc (Vitis vinifera L.). J. Agric. Food Chem. 60(37), 9454-9461.

Swiegers, J.H. \& Pretorius, I.S., 2005. Yeast modulation of wine flavor Adv. Appl. Microbiol. 57, 131-175.

Walker, R.R., Blackmore, D.H., Clingeleffer, P.R., Kerridge, G.H., Rühl, E.H. \& Nicholas, P.R., 2005. Shiraz berry size in relation to seed number and implications for juice and wine composition. Aust. J. Grape Wine Res. 11(1), 2-8.

Wen, Y.Q., Cui, J., Zhang, Y., Duan, C.Q. \& Pan, Q.H., 2014. Comparison of organic acid levels and $L$-IdnDH expression in Chinese-type and Europeantype grapes. Euphytica 196(1), 63-76.

Wong, D.C.J., Gutierrez, R.L., Dimopoulos, N., Gambetta, G.A. \& Castellarin, S.D., 2016. Combined physiological, transcriptome, and cis-regulatory element analyses indicate that key aspects of ripening, metabolism, and transcriptional program in grapes (Vitis vinifera L.) are differentially modulated accordingly to fruit size. BMC Genomics 17(1), 416.

Zhang, M.X., Pan, Q.H., Yan, G.L. \& Duan, C.Q., 2011. Using headspace solid phase micro-extraction for analysis of aromatic compounds during alcoholic fermentation of red wine. Food Chem. 125(2), 743-749. 